\title{
Trachyspic acid 19-butyl ester, a new inhibitor of Plk1 polo box domain-dependent recognition from uncharacterized fungus RKGS-F2684
}

\author{
Toshihiko Nogawa $^{1}$, Noriko Ogita ${ }^{1}$, Yushi Futamura ${ }^{1}$, Shigenori Negishi ${ }^{2}$, Nobumoto Watanabe ${ }^{3}$ \\ and Hiroyuki Osada ${ }^{1}$
}

The Journal of Antibiotics (2017) 70, 705-707; doi:10.1038/ja.2016.167; published online 18 January 2017

Polo-like kinase 1 (Plk1) is a serine-threonine protein kinase that possesses many essential functions during mitosis and is one of the key regulators of mitotic cell division. ${ }^{1,2}$ Although it has a catalytic domain of protein kinase at its N-terminus, it possesses a phosphopeptide binding domain named polo box domain (PBD) at its C-terminus. ${ }^{3,4} \mathrm{PBD}$ binds to other protein in a phosphorylation dependent manner. PBD-dependent binding not only is important for the subcellular localization, but is also necessary for the targeting of Plk1 to specific substrates. ${ }^{3}$

Plk1 is frequently overexpressed in many cancers and inhibition of Plk1 by antisence oligonucleotides or small interfering RNA (siRNA) is highly effective in inhibiting cancer cell proliferation. The reduction of Plk1 is also shown to induce tumor regression in mouse xenograft model. ${ }^{5}$ Thus, Plk1 is considered to be an attractive target for the treatment of human cancers. ${ }^{6-8}$ Several inhibitors of its catalytic activity are developed and some of them have proceeded to clinical trials. ${ }^{9,10}$ We established a screening system for the inhibitors of PBD-dependent binding. ${ }^{11}$ In this system, the open reading frame of a green fluorescent protein (GFP) is fused to $\mathrm{PBD}$ and expressed in bacteria. Target phosphopeptides for the PBD binding sequence are chemically synthesized and bound covalently to maleimide-activated 96-well plates. The binding of GFP-PBD to the phosphopeptides was quantitated through spectrofluorometry. Using this system, we have obtained purpurogallin, a benzotropolone-containing natural compound from nutgalls as an inhibitor of PBD. ${ }^{11}$ Several other inhibitors of PBD are also identified by other groups but currently no clinical trials have been reported. ${ }^{12}$

We have developed a structure based compound isolation technique named NPPlot (Natural Products Plot), where secondary metabolites from microorganisms are analyzed by their MW and retention time on DAD-LC/MS. ${ }^{13}$ These analytical data are accumulated and used for the spectral database establishment. Using the method, we have isolated several new metabolites with unprecedented skeletons from microbial sources, such as verticilactam, ${ }^{14}$ spirotoamides, ${ }^{15}$ pyrrolizilactone ${ }^{16}$ and recently opantimycin A. ${ }^{17}$
In the present study, we combined our high-throughput screening system for PBD inhibitors and the methodology of the fractionation of microbial metabolites with spectral database. Using these techniques, a new 5,5-spiroacetal metabolite, trachyspic acid 19-butyl ester (1) together with a known metabolite trachyspic acid (2) ${ }^{18}$ with potent PBD inhibitory activity was isolated from uncharacterized fungus RKGS-F2684 (Figure 1). We report here the isolation, structure and biological activity of 1 .

In the course of screening from about 3000 microbial extracts using our high-throughput screening system, we found that the extracts from fungal strain RKGS-F2684, which was isolated from a soil sample collected in Kumamoto, Japan in 1995, contained potent inhibitory activity. An ethyl acetate soluble extract from 31 culture broth of the fungus was separated by $\mathrm{SiO}_{2}$-medium-pressure liquid chromatography (MPLC) to 8 fractions. The active fraction was further separated by C18MPLC to 65 sub-fractions. Each fraction was analyzed by the technique of NPPlot using DAD-LC/MS and the PBD binding inhibitory activity of them was also examined. Among these fractions, the inhibitory activity existed roughly at two groups of fractions peaked at 28th and 35th, respectively. Both groups contained metabolites with identical UV absorption spectrum of $\lambda_{\max }$ value of $280 \mathrm{~nm}$ to each other, although their $\mathrm{m} / \mathrm{z}$ value (between 400 and 500) was not identical. The compound in the peak at 35th fraction was separated by C18-HPLC to afford a crude compound 1. It was further purified by 12 cycles of C18-recycle HPLC and $5.5 \mathrm{mg}$ of 1 as colorless amorphous was obtained (Table 1). The other compound in the peak at 28th fraction was purified by C18-HPLC and $25.4 \mathrm{mg}$ of compound 2 as colorless amorphous was obtained. Compound 2 was identified to be trachyspic acid by direct comparison of the physiocochemical properties with those of standard sample. ${ }^{18}$

The molecular formula of compound $\mathbf{1}$ was determined to be $\mathrm{C}_{24} \mathrm{H}_{36} \mathrm{O}_{9}$ by HRFABMS (found: $m / z 469.2396[\mathrm{M}+\mathrm{H}]^{+}$, calcd for $\mathrm{C}_{24} \mathrm{H}_{37} \mathrm{O}_{9}, 469.2438$ ). The identical UV absorption spectrum with that of 2 and IR spectrum, which showed a strong absorption at $1718 \mathrm{~cm}^{-1}$ implying the presence of ester, suggested that 1 was a related metabolite to 2 . This was also supported by ${ }^{1} \mathrm{H}$ NMR spectrum

${ }^{1}$ RIKEN Center for Sustainable Research Science, Chemical Biology Research Group, Saitama, Japan; ${ }^{2}$ Alcohol Research and Institute, OENON Holdings, Inc, Yamanashi, Japan and ${ }^{3}$ RIKEN Center for Sustainable Research Science, Bio-Active Compounds Discovery Research Unit, Saitama, Japan

Correspondence: Dr H Osada, RIKEN Center for Sustainable Research Science, Chemical Biology Research Group, 2-1 Hirosawa, Wako, Saitama 351-0198, Japan.

E-mail: hisyo@riken.jp

This article is dedicated to the issue celebrating Professor Satoshi Ōmura for winning the 2015 Nobel Prize in Physiology or Medicine.

Received 6 October 2016; revised 5 December 2016; accepted 15 December 2016; published online 18 January 2017 


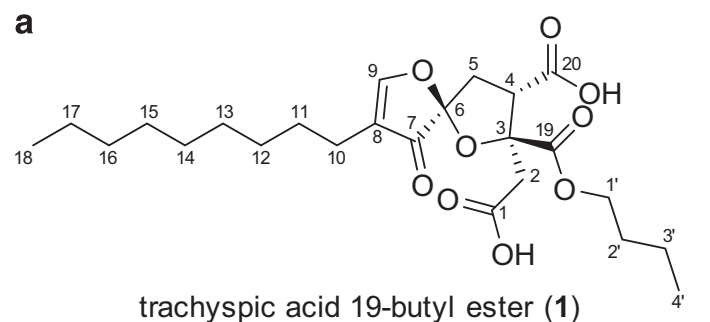
trachyspic acid 19-butyl ester (1)<smiles>CCCCCCCCCC1=CO[C@]2(C[C@H](C(=O)O)[C@](CC(=O)O)(C(=O)O)O2)C1=O</smiles>

trachyspic acid (2)

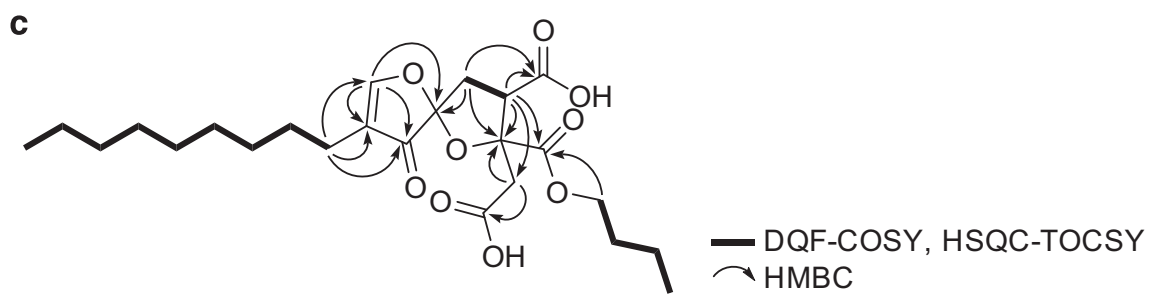

Figure 1 Structures of compounds $\mathbf{1}$ (a) and $\mathbf{2}$ (b), and Key 2D NMR correlations of $\mathbf{1}$ (c).

Table 1 Physicochemical properties of compound 1

\begin{tabular}{ll}
\hline Appearance & Colorless amorphous \\
\hline Optical rotation $\left(\mathrm{CHCl}_{3}\right)$ & {$[\alpha]_{589}^{26}+6.0^{\circ}(\mathrm{c} \mathrm{O} 0.1)$} \\
Molecular formula & $\mathrm{C}_{24} \mathrm{H}_{36} \mathrm{O}_{9}$ \\
UV $(\mathrm{MeOH}) \lambda_{\max }(\log \varepsilon ; \mathrm{nm})$ & $280(3.53)$ \\
$\mathrm{IR}($ ATR $) \nu_{\max }\left(\mathrm{cm}^{-1}\right)$ & $3455,2956,2925,2854,1718,1616,1405$, \\
& $1207,1066,935$ \\
ESIMS $(\mathrm{m} / \mathrm{z})$ & $469[\mathrm{M}+\mathrm{H}]^{+}$ \\
HRFABMS $(\mathrm{m} / \mathrm{z})$ & Found $469.2396[\mathrm{M}+\mathrm{H}]^{+}$ \\
& calcd $\mathrm{C}_{24} \mathrm{H}_{37} \mathrm{O}_{9}, 469.2438$ \\
\hline
\end{tabular}

(Supplementary Figure S1). It showed similar signals with those of 2 including a broad signal at 1.23 p.p.m. of the integration value of $12 \mathrm{H}$, except for additional methyl signal at 0.89 p.p.m. $(3 \mathrm{H}, \mathrm{t}, J=7.3 \mathrm{~Hz})$, two methylene signals at 1.35 and 1.62 p.p.m. $(2 \mathrm{H}$, sextet, $J=7.3 \mathrm{~Hz}$ and $2 \mathrm{H}, \mathrm{m}$, respectively) and an oxygenated methylene signal at 4.21 p.p.m. $(2 \mathrm{H}, \mathrm{m}) .{ }^{13} \mathrm{C}$ NMR spectrum also showed identical signals with those of $\mathbf{2}$ including a characteristic quaternary signal at 107.6 p.p.m. implying the presence of spiroacetal core structure, except for additional one methyl signal at 13.5 p.p.m., two methylene signals at 18.9 and 30.2 p.p.m., and one oxygenated methylene signal at 66.5 p.p.m., which were confirmed by ${ }^{13} \mathrm{C}$ DEPT experiment (Supplementary Figures S2 and S3). These observations suggested that $\mathbf{1}$ was a butyl ester at one of the three carboxylic acids of $\mathbf{2}$. To verify the precise structure, 2D NMR spectra including HSQC, double quantum filtered (DQF)-COSY, HSQC-TOCSY and HMBC were investigated (Figure 1c). The connections between protons and carbons were established by correlations in the HSQC spectrum (Supplementary Figure S4). The DQF-COSY and HSQC-TOCSY spectra confirmed the presence of two alkyl chains consisting of 9 and 4 carbons and the connection between C-4 and C-5 (Supplementary Figures S5 and S6). The 5,5-spiroacetal structure was confirmed by the HMBC correlations from $\mathrm{H}-4$ to $\mathrm{C}-3$, from $\mathrm{H}-5$ to C-3 and 6 and from H-9 to C-6, 7 and 8 with consideration of ${ }^{13} \mathrm{C}$ chemical shift value and index of hydrogen deficiency (Supplementary Figure S7). The HMBC spectrum also confirmed the attachment of the long alkyl chain to $\mathrm{C}-8$ by correlations from $\mathrm{H}-10$ to $\mathrm{C}-7,8$ and 9. A butyl ester at $\mathrm{C}-19$ was established by $\mathrm{HMBC}$ correlation from $\mathrm{H}-1^{\prime}$ to $\mathrm{C}-19$. Based on the above results the planer structure was determined to be trachyspic acid 19-butyl ester. The relative stereo structure of $\mathbf{1}$
Table $2{ }^{1} \mathrm{H}$ and ${ }^{13} \mathrm{C}$ NMR chemical shifts of compound 1 in $\mathrm{CDCl}_{3}$

\begin{tabular}{|c|c|c|c|c|}
\hline Position & & $\delta_{C}$ & $\delta_{H}$ & Multiplicity (J in Hz) \\
\hline 1 & & 175.9 & - & \\
\hline \multirow[t]{2}{*}{2} & & 38.6 & 3.23 & d (17.4) \\
\hline & & & 3.37 & $d(17.4)$ \\
\hline 3 & & 87.8 & - & \\
\hline 4 & & 45.6 & 4.34 & dd $(12.8,6.9)$ \\
\hline \multirow[t]{2}{*}{5} & $\beta$ & 38.2 & 2.33 & $\mathrm{dd}(12.8,6.9)$ \\
\hline & $\alpha$ & & 2.66 & $\mathrm{dd}(12.8,12.8)$ \\
\hline 6 & & 107.6 & - & \\
\hline 7 & & 197.5 & - & \\
\hline 8 & & 118.4 & - & \\
\hline 9 & & 172.4 & 7.83 & $\mathrm{~s}$ \\
\hline 10 & & 21.0 & 2.08 & $2 \mathrm{H}, \mathrm{t}(7.3)$ \\
\hline 11 & & 27.8 & 1.42 & $2 \mathrm{H}, \mathrm{m}$ \\
\hline 12 & & 29.2 & 1.23 & $12 \mathrm{H}, \mathrm{br}^{\mathrm{a}}$ \\
\hline 13 & & 29.2 & 1.23 & a \\
\hline 14 & & 29.2 & 1.23 & a \\
\hline 15 & & 29.4 & 1.23 & a \\
\hline 16 & & 31.8 & 1.23 & a \\
\hline 17 & & 22.6 & 1.23 & a \\
\hline 18 & & 14.0 & 0.85 & $3 \mathrm{H}, \mathrm{t}(6.9)$ \\
\hline 19 & & 168.3 & - & \\
\hline 20 & & 176.6 & - & \\
\hline $1^{\prime}$ & & 66.5 & 4.21 & $2 \mathrm{H}, \mathrm{m}$ \\
\hline $2^{\prime}$ & & 30.2 & 1.62 & $2 \mathrm{H}, \mathrm{m}$ \\
\hline $3^{\prime}$ & & 18.9 & 1.35 & $2 \mathrm{H}$, sextet $(7.3)$ \\
\hline $4^{\prime}$ & & 13.5 & 0.89 & $3 \mathrm{H}, \mathrm{t}(7.3)$ \\
\hline
\end{tabular}

${ }^{1} \mathrm{H}$ and ${ }^{13} \mathrm{C}$ NMR spectra were recorded at 500 and $125 \mathrm{MHz}$, respectively.

aThe ${ }^{1} \mathrm{H}$ NMR signal from $\mathrm{H}-12$ to $\mathrm{H}-17$ were observed as a broad signal with an integration value of $12 \mathrm{H}$.

was established as same as those of 2 by the comparison of NMR chemical shit values between 1 and 2 in both of DMSO- $d_{6}$ and MeOH$d_{4}$ and NOESY correlations in $\mathrm{CDCl}_{3}$ between $\mathrm{H}-4$ and $\mathrm{H}-5 \beta$ and $\mathrm{H}-5 \beta$ and $\mathrm{H}-2$ ' suggesting they were on the same side (Supplementary Figure S8). ${ }^{18,19}$ The absolute configuration was supposed to be (3S, $4 \mathrm{~S}$, $6 S)$ by the same positive-specific rotation value with that of $2\left(1:+6.0^{\circ}\right.$ (c 0.1, $\left.\mathrm{CHCl}_{3}\right)$, 2: our experiment $/+3.7^{\circ}\left(c 0.1, \mathrm{CHCl}_{3}\right)$, literatures/ $+3.1^{\circ}$ (c 1.0, MeOH), ${ }^{18}+3.1^{\circ}(\text { c } 0.3, \mathrm{MeOH})^{20}$ and $+7.1^{\circ}$ (c 0.3, $\left.\mathrm{CH}_{2} \mathrm{Cl}_{2}\right)^{20}$ ). Therefore, the structure of 1 was determined to be $(3 S, 4 S, 6 S)$-trachyspic acid 19-butyl ester (Table 2). 
a

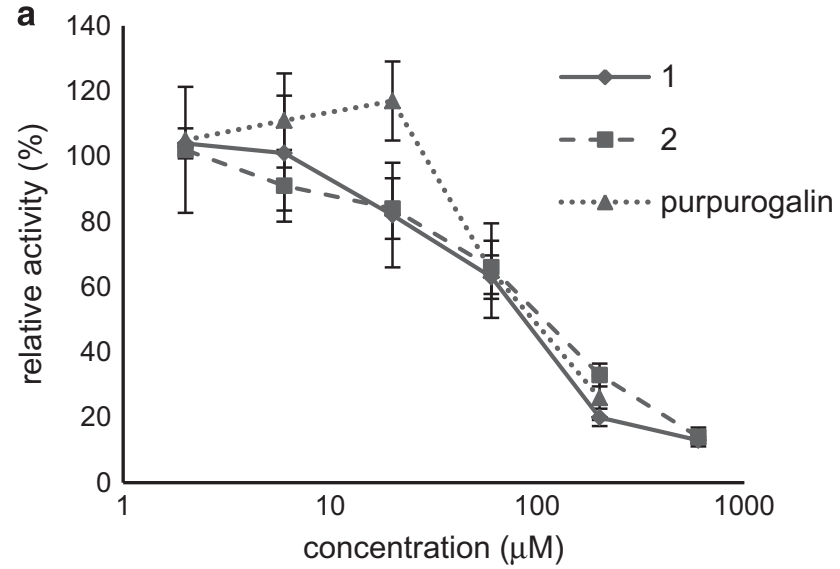

b<smiles></smiles>

Figure 2 Effect of compounds 1 and 2 on PBD-dependent binding. (a) Effect of various concentration. (b) Structure of purpurogallin.

The inhibition activity of PBD-dependent binding of compounds 1 and 2 was evaluated in vitro with purpurogallin as a positive control (Figure 2). They showed the same range of activity to that of purpurogallin with $\mathrm{IC}_{50}$ values of 102 (1), 128 (2) and 114 (purpurogallin) $\mu \mathrm{M}$. Several Plk1 inhibitors have been reported including purpurogallin, ${ }^{6-8}$ however, most of them contain an aromatic moiety in their molecules apart from the structures of 1 and 2, which have a 5,5-spiroacetal core with alkyl chain and tricarboxylic acid moiety. Also 2 has been isolated as an inhibitor of heparanase and the activity has not been investigated in detail. ${ }^{18}$ Therefore, we are going to continue to evaluate the detail of activity in vivo and will report the finding elsewhere.

In summary, the new inhibitor of PBD-dependent binding, trachyspic acid 19-butyl ester was isolated from the fungus RKGSF2684 based on the combination of high-throughput screening system and the fraction library. Even though compound 1 might be an artifact from trachyspic acid (2) during the extraction process using butanol, the isolation and structure of $\mathbf{1}$ is worth to be reported for the new type of activity and structural difference against known Plk1 inhibitors. Also we have detected other derivatives having identical UV absorption spectra with slightly different $m / z$ values, which are speculated as related derivatives of $\mathbf{1}$, in the MPLC fractions. The fractions containing such derivatives showed similar range of Plk1 activity and it suggests that trachyspic acid and its derivatives may become an attractive lead compound of Plk1 inhibition and a drug for cancer therapy. These results showed that the screening system that we had established for identification of PBD-dependent binding from chemical library was applicable to natural extracts as a powerful tool to search and identify active metabolites in bioassay guided separations. Also our microbial fraction library should be useful material for a high-throughput screening system designed for a chemical library.

\section{CONFLICT OF INTEREST}

The authors declare no conflict of interest.

\section{ACKNOWLEDGEMENTS}

We thank Dr T Takatsu of Daiichi-Sankyo Co, Ltd for providing the standard trachyspic acid. We also thank Dr S Takahashi of RIKEN for useful discussion about strucutures, and Dr M Mori, Ms A Okano and Ms E Sanada of RIKEN for technical assistance. This work was supported in part by JSPS KAKENHI Grant Numbers 24248022 and 26450148, Japan Agency for Medical Research and Development and grant-in-aid from Research Program on Hepatitis from the Japan Agency for Medical Research and Development, AMED.

1 Barr, F. A., Sillje, H. H. \& Nigg, E. A. Polo-like kinases and the orchestration of cell division. Nat. Rev. Mol. Cell. Biol. 5, 429-441 (2004).

2 van Vugt, M. A. \& Medema, R. H. Getting in and out of mitosis with Polo-like kinase-1. Oncogene 24, 2844-2859 (2005).

3 Elia, A. E., Cantley, L. C. \& Yaffe, M. B. Proteomic screen finds pSer/pThr-binding domain localizing Plk1 to mitotic substrates. Science 299, 1228-1231 (2003).

4 Elia, A. E. et al. The molecular basis for phosphodependent substrate targeting and regulation of Plks by the Polo-box domain. Cell 115, 83-95 (2003).

5 Strebhardt, K. \& Ullrich, A. Targeting polo-like kinase 1 for cancer therapy. Nat. Rev. Cancer 6, 321-330 (2006).

6 Lenart, P. et al. The small-molecule inhibitor BI 2536 reveals novel insights into mitotic roles of polo-like kinase 1. Curr. Biol. 17, 304-315 (2007).

7 McInnes, C. et al. Inhibitors of Polo-like kinase reveal roles in spindle-pole maintenance. Nat. Chem. Biol. 2, 608-617 (2006).

8 Santamaria, A. et al. Use of the novel PIk1 inhibitor ZK-thiazolidinone to elucidate functions of Plk1 in early and late stages of mitosis. Mol. Biol. Cell 18 4024-4036 (2007).

9 Gilmartin, A. G. et al. Distinct concentration-dependent effects of the polo-like kinase 1-specific inhibitor GSK461364A, including differential effect on apoptosis. Cance Res. 69, 6969-6977 (2009).

10 Jimeno, A. et al. Phase I study of ON 01910. Na, a novel modulator of the Polo-like kinase 1 pathway, in adult patients with solid tumors. J. Clin. Oncol. 26, 5504-5510 (2008)

11 Watanabe, N. et al. Deficiency in chromosome congression by the inhibition of Plk1 polo box domain-dependent recognition. J. Biol. Chem. 284, 2344-2353 (2009).

12 Watanabe, N. \& Osada, H. Small molecules that target phosphorylation dependent protein-protein interaction. Bioorg. Med. Chem. 24, 3246-3254 (2016).

13 Osada, H. \& Nogawa, T. Systematic isolation of microbial metabolites for natural products depository (NPDepo). Pure Appl. Chem. 84, 1407-1420 (2012).

14 Nogawa, T. et al. Verticilactam, a new macrolactam isolated from a microbial metabolite fraction library. Org. Lett. 12, 4564-4567 (2010).

15 Nogawa, $T$. et al. Spirotoamides A and B, novel 6,6-spitoaccetal polyketides isolated from a microbial metabolite fraction library. J. Antibiot. 65, 123-128 (2012).

16 Nogawa, T. et al. Pyrrolizilactone, a new pyrrolizidinone metabolite produced by a fungus. J. Antibiot. 66, 621-623 (2013).

17 Nogawa, T. et al. Opantimycin A, a new metabolite isolated from Streptomyces sp. RK881355. J. Antibiot. 70, 222-225 (2017).

18 Shiozawa, $\mathrm{H}$. et al. Trachyspic acid, a new metabolite produced by Talaromyces trachyspermus, that inhibits tumor cell heparanase: taxonomy of the production strain, fermentation, isolation, structural elucidation, and biological activity. J. Antibiot. 48, 357-362 (1995).

19 Hirai, K., Ooi, H., Esumi, T., Iwabucchi, Y. \& Hatakeyama, S. Total synthesis of $( \pm)$-trachyspic acid and determination of the relative configuration. Org. Lett. 5, 857-859 (2003).

20 Zammit, S. C., Ferro, V., Hammond, E. \& Rizzacasa, M. A. Enantiospecific synthesis of the heparanase inhibitor (+)-trachyspic acid and stereoisomers from a common precursor. Org. Biomol. Chem. 5, 2826-2834 (2007).

Supplementary Information accompanies the paper on The Journal of Antibiotics website (http://www.nature.com/ja) 